\title{
Some Structural and Optical Properties of sprayed Iron Oxide Thin films
}

\author{
I. B. I. Tomsah \\ Physics Department, College of Science, Qassim University, P. O. 6644, 51452, Buryadh, Kingdom of Saudi \\ Arabia
}

\begin{abstract}
In this paper $\alpha-\mathrm{Fe}_{2} \mathrm{O}_{3}$, thin films were prepared by spray pyrolysis technique via spraying $\mathrm{FeCl}_{3} \cdot 6 \mathrm{H}_{2} \mathrm{O}\left(10^{-2} \mathrm{M}\right)$ based aqueous solution with a spray flow of $8 \mathrm{ml} / \mathrm{min}$ onto heated glass substrates at $350{ }^{\circ} \mathrm{C}$. After deposition, rust red and amorphous films was obtained. After a heat treatment at $400{ }^{\circ} \mathrm{C}$ for six hours, the thin films are well crystallized. In order to study the surface morphology of the films and their crystalline structure, an electron scanning microscope (SEM) and X-ray diffraction were used (XRD). A UV-Vis-NIR spectrophotometer in the wavelength range 200-2500 $\mathrm{nm}$ was used to carry out the transmittance and the reflectance of the iron oxide films. The study of the optical properties of the iron oxide thin films was completed by the data acquired using a variable angle spectroscopic ellipsometer in the range 400-1800 $\mathrm{nm}$ of wavelength. The results reveal that the sprayed thin films were amorphous and after the heat treatment, the films crystallize in the $\alpha-\mathrm{Fe}_{2} \mathrm{O}_{3}$ phase. SEM images show compact and homogeneous films, the estimated optical band gap for allowed direct transition of the iron oxide films was found to be $2.15 \mathrm{eV}$. On the other hand, the calculated thickness of the films from ellipsometry modeling is about $710 \mathrm{~nm}$.
\end{abstract}

Keywords: $\alpha-\mathrm{Fe}_{2} \mathrm{O}_{3}$ thin films; ellipsometry; optical constants; spray pyrolysis.

\section{Introduction}

In recent years, the elaboration and studies of iron oxide, whether in powder or thin films and with different structures and morphologies has attracted the attention of researchers in different fields of technology. Iron oxides used in a wide-ranging of applications such as coloring, coating material, catalysts, gas sensing material, impurity control agent in soil or water, electromagnetic material, biological applications, energy conversion, energy storage system and so on [1,2]. There are a wide variety of iron oxides and oxyhydroxides, in total sixteen known phases of $\mathrm{Fe}_{\mathrm{x}} \mathrm{O}_{\mathrm{y}} \mathrm{H}_{\mathrm{z}}$ are enumerated $[1,3]$. The $\alpha-\mathrm{Fe}_{2} \mathrm{O}_{3}$, also called hematite, is the most common phase of iron oxide in nature. It's an n-type semiconductor, having a small band gap of $2.2 \mathrm{eV}$ and is the most stable iron oxide under ambient conditions. This relatively low band gap value allows to hematite to absorb about $40 \%$ of the sunlight, which is a significant advantage for its use in solar energy conversion $[4,5]$.

Recently, several physical and chemical techniques have been used to elaborate iron oxides powder [6], such as sonochemical technique [7], chemical precipitation [8,9] and hydrothermal method [10]. For thin films, sol-gel [11, 12], chemical bath deposition [13], reactive evaporation [14, 15] and spray pyrolysis [16-21]. The elaboration techniques and also the corresponding references given above are not exhaustive.

In this work, an iron oxide thin film by chemical spray pyrolysis method has been elaborated; this approach is an efficient way to prepare homogeneous thin films. This technique is used by many researchers to deposit thin layers of iron oxides using different chemical solutions [16-22].

The iron oxide thin films were elaborated by spraying an aqueous solution $\left(10^{-2} \mathrm{M}\right)$ of iron trichloride $\left(\mathrm{FeCl}_{3}\right)$, on glass substrates at a relatively low temperature $\left(350{ }^{\circ} \mathrm{C}\right)$. These sprayed thin films are amorphous, and after an annealing at $400{ }^{\circ} \mathrm{C}$ during six hours, the films crystallize in the $\alpha-\mathrm{Fe}_{2} \mathrm{O}_{3}$ phase. This heat treatment was carried out under ambient atmosphere with a small rise in temperature which is of the order of $30 \mathrm{deg} . / \mathrm{hour}$; this way of proceeding allows to obtain homogeneous and well crystallized thin films. The obtained thin films are chemically and mechanically stable.

The $\alpha-\mathrm{Fe}_{2} \mathrm{O}_{3}$ films were investigated by XRD, SEM, UV-VIS-NIR spectroscopy and ellipsometry.

\section{Experimental Details}

Thin films of iron oxide $\mathrm{Fe}_{2} \mathrm{O}_{3}$ have been prepared by chemical pyrolysis technique. A preheated glass slides at $350 \mathrm{C}$ was used as substrates. A $0.01 \mathrm{M}$ for $\mathrm{FeCl}_{3}$ (Sigma-Aldrich) diluted with deionized water was used to obtain the starting solution for deposition. The nozzle is $50 \mathrm{~cm}$ away, from the substrates; the jet flow rate and the spraying time, were about $8 \mathrm{ml} / \mathrm{min}$ and $30 \mathrm{~min}$, respectively. Nitrogen was used as a gas vector.

The morphology of the obtained thin films was characterized by scanning electron microscope (SEM) type JOEL model JSM-6380 LA (Japan) and their structure by X-ray diffraction (XRD) using Shimadzu Diffractometer XRD 6000, Japan, which utilizing CuK $\alpha 1$ radiation $(\lambda=1.54056 \AA)$. XRD data was performed by 
step-scan modes, in a $2 \theta$ range of $10^{\circ}-65^{\circ}$ with a step-size and a step time of $0.02^{\circ}$ and $0.6 \mathrm{~s}$, respectively.

To measure the transmittance and the total reflectance of the crystallized iron oxide films a double-beam computerized spectrophotometer (JASCO UV-Vis-NIR-570) was used. The data were recorded at normal incidence of light and at room temperature for wavelengths between 200 and $2500 \mathrm{~nm}$.

The spectroscopic ellipsometry (SE) data for $\mathrm{Fe}_{2} \mathrm{O}_{3}$ thin films were carried out using a J.A.

Woollam variable angle spectroscopic ellipsometer, in the wavelength range 400-1800 $\mathrm{nm}$. The SE data was acquired at an angle of incidences of $55^{\circ}, 65^{\circ}, 75^{\circ}$ and $85^{\circ}$. The measurements were conducted at room temperature, and the spectroscopic ellipsometry data was analyzed using the Complete EASE software from J.A. Woollam Co., Inc.

The band gap energy $\mathrm{E}_{\mathrm{g}}$ was estimated, first, using the transmittance and reflectance spectra, secondly from the results of the ellipsometric measurements.

\subsection{Structure and Morphology:}

\section{Results And Discussion}

XRD measurements were performed to determine the crystal structure and identification of phases of sprayed iron oxide thin films. X-ray diffraction analysis was carried out of angle $2 \theta$ in the range of 10 to 65 degree. Fig. 1 shows a typical XRD patterns of crystallized iron oxide $\mathrm{Fe}_{2} \mathrm{O}_{3}$ thin film of an estimated thickness of $1 \mu \mathrm{m}$ deposited onto a glass substrate. Existence of peaks matching to planes (012), (104), (110), (006), (113), (202), (024), (116), (211), (122), (018), (214) and (300) point toward hematite $\alpha-\mathrm{Fe}_{2} \mathrm{O}_{3}$ phase. In agreement with JCPDS card 33-0664 the film have rhombohedral type structure, this study has been investigated with QualX software [23].

The SEM micrographs of $\alpha-\mathrm{Fe}_{2} \mathrm{O}_{3}$ films obtained after annealing have been depicted in Fig. 2., due to the spray technique. One can be seen from these images that the samples are continuous, compact, and homogeneous without cracks and well adherent growth onto the substrate with little surface roughness. It is covered by overgrown micro-wires randomly distributed over the entire surface. The average length is $20 \mu \mathrm{m}$.

\subsection{Optical properties:}

\subsubsection{Transmittance and reflectance spectra:}

Figure 3 shows the representative spectra of both transmission $T(\lambda)$ and reflectance $R(\lambda)$ of the $\alpha-\mathrm{Fe}_{2} \mathrm{O}_{3}$ thin films deposited onto a glass substrate.

These spectra show that these thin layers begin to be transparent from a wavelength of the order of $550 \mathrm{~nm}$, and a maximum of $65 \%$ transparency for a wavelength close to $2370 \mathrm{~nm}$. The corresponding transmission and reflection spectra approach the semiconductor behavior with the appearance of interferential fringes due to multiple reflections. The amplitude of the interference fringes indicates the extent of the homogeneity of the films; the homogeneity of the thin films is better as the amplitude of the fringes is large. Significant interference fringes appear, for thin films with highly reflecting surface and with no much absorption in bulk. Thus, it can be said that the sprayed iron oxide layers are homogeneous and can be used as transparent thin films in optoelectronic devices. For $\lambda<1000 \mathrm{~nm}$, the interference fringes disappear due to the onset of absorption. The absorption can be caused by either localized states into the forbidden band or the scattering from a rough surface.

Using the interference fringes on $\mathrm{R}(\square)$ and $\mathrm{T}(\square)$ spectra,the thickness $\mathrm{d}$ of the film can be estimated, in the domain of transparency $(550-2500 \mathrm{~nm})$, by applying the relationship [24-26]:

$d=\frac{1}{2} \frac{\lambda_{\max }^{p} \lambda_{\max }^{p+1}}{\lambda_{\max }^{p} n\left(\lambda_{\max }^{p+1}\right)-\lambda_{\max }^{p+1} n\left(\lambda_{\max }^{p}\right)}$

Where $p$ and $p+1$ are the orders of two successive maxima of reflection, $\lambda_{\max }$ is the wavelength at the maximum and $\mathrm{n}$ is the value of refractive index given by ellipsometry measurement. The value of the thickness found here, is not very different from that deduced by that estimated by double weighing ( $0.9 \mu \mathrm{m}$ instead of 1 $\mu \mathrm{m})$.

The optical absorption coefficient $\alpha$ is calculated by the following approximate relationship valid in mean absorption zone $(550 \mathrm{~nm} \leq \lambda \leq 850 \mathrm{~nm})$ :

$e^{-\alpha d}=\frac{\left[T^{-2}(1-R)^{4}+4 R^{2}\right]^{0.5}-T^{-1}(1-R)^{2}}{2 R^{2}}$ 
To determine the value of the optical band gap $E_{\mathrm{g}}$ corresponding to direct band gap transitions, an $(\alpha \mathrm{h} v)^{2}$ versus the incident photon energy hv plot (Fig. 4) is used according to the formula [27]:

$(\alpha h v)^{2}=A\left(h v-E_{g}\right)$

The constant A is given by $A=\left[\frac{e^{2}}{n c h^{2} m_{e}^{*}}\right]\left(2 m_{r}\right)^{3 / 2}$, where $m_{e}^{*}$ and $m_{r}$ are the effective and reduced masses of charge carries, respectively. The optical band gap estimated at $2.17 \mathrm{eV}$ is determined by extrapolating the linear part of a plot of $(\alpha h v)^{2}$ with the abscissa axis (h $\square$ ) Which is in good agreement with the value obtained elsewhere [5, 18, and 22] for a similar phase.

\subsubsection{Ellipsometric Results}

$\mathrm{SE}$ is one of the preferred methods for studying thin films, especially their optical constants. The method is non-destructive, robust and its principles and applications are explained in many references [28-31]. The measurements are based on the change in polarization of the reflected light from the sample, more precisely change in ellipsometric angles $\Psi$ and $\Delta$, by measuring ratio $\mathrm{F}$ of complex reflectance coefficients of perpendicular $\tilde{r}_{p}$ and parallel $\tilde{r}_{s}$ components of polarized light:

$$
F=\frac{\tilde{r}_{p}}{\tilde{r}_{s}}=\tan (\Psi) \exp (i \Delta)
$$

The values of $\Psi$ and $\Delta$ for each wavelength does not contain any readily useful information, and measured data need to be interpreted through a model which most of the today ellipsometers are capable.

The J.A. Woollam Corporation developed WVAS32 software package was used to model the ellipsometric data faithfully. The best-match model data are also shown and can be seen to fit well with the experimental results, confirming the efficient of the used model.

The model used to interpret the SE data consisted of two layers: semi-infinite non-absorbing glass substrate and a transparent dielectric material $\mathrm{Fe}_{2} \mathrm{O}_{3}$ modeled by Cauchy layer taking into account the roughness of the film. This model is also a mathematical dispersion one obtained from a series expansion of the Sellmeier layer model, and it is, therefore, an approximation function of it. The Cauchy dispersion relation can be expressed by [28-31]:

$$
\begin{aligned}
& n(\lambda)=A+\frac{B}{\lambda^{2}}+\frac{C}{\lambda^{4}} \\
& k(\lambda)=\alpha^{\prime} \exp \left(\beta\left(\frac{1}{\lambda}-\frac{1}{\lambda_{0}}\right)\right)
\end{aligned}
$$

All the Cauchy parameters and the thickness of the iron oxide layer were used as variable fit parameters. Figure 3 shows the best fit of the experimental $\Psi$ and $\Delta$ of the iron oxide films, a good agreement between the fitted and measured data is evident. Moreover, thicknesses measured with this layer model were found consistent with the double weighing measurements. Double weighing gave an average of $1 \mu \mathrm{m}$ thickness for iron oxide, ellipsometry measurements on some samples with the same film gave an average thickness of $710 \mathrm{~nm}$, which is $20 \%$ less than the results deduced from spectrophotometry measurements $0.9 \mu \mathrm{m}$.

The optical constants, such as the refractive index $\mathrm{n}$ and the extinction coefficient $\mathrm{k}$, can be deduced from $\Psi$ and $\Delta$ data. The thickness of the layer and the MSE (mean square error) expressing the accuracy of the fit determined by the software are summarized in Table 1 .

The MSE value indicates the precision of the fit, the best agreement between the fitted and measured data is obtained for a value of MSE closest to one, and this is the case in this work. [28]. Indeed, The MSE values for sprayed iron oxide thin films show an average of 1.3, indicating a good agreement between the measured and model generated SE data.

The change of refractive index $\mathrm{n}$ and extinction coefficient $\mathrm{k}$, as a function of wavelength for the iron oxide films obtained here, are shown in Figure 5 and Figure 6, respectively. The refractive index increases with the decreases of the wavelength in the visible region were observed. The maximum for the refractive index and extinction coefficient of the iron oxide film obtained are about 2.7 for $\mathrm{n}$ and 1.2 for $\mathrm{k}$, at wavelength $1690 \mathrm{~nm}$ and $370 \mathrm{~nm}$ respectively. Similar values for these optical parameters of iron oxide films obtained by different methods were reported in the literature. The values of the refractive index $n$ and the extinction coefficient $k$, for the sol-gel $\mathrm{Fe}_{2} \mathrm{O}_{3}$ multilayer, obtained elsewhere [32, 33], varies approximatively, from 1.6 to 2.6 and from 0 to 0.5 , respectively.

Nevertheless, the calculated values of the refractive index and extinction coefficient from 
transmittance and reflectance measurements as reported by Akl [18], varies in the range of $0.5<\mathrm{n}<1.25$ and $0.1<\mathrm{k}<0.5$ for crystalline $\alpha-\mathrm{Fe}_{2} \mathrm{O}_{3}$ sprayed thin films. One notices a rather large variation from the results found in this work. This disparity is probably due to the results given by Akl are based on a theoretical calculation based on the values of $\mathrm{T}$ and $\mathrm{R}$, whereas, in this work $\mathrm{n}$ and $\mathrm{k}$ were found from ellipsometric measurements.

In this study, the variation of the refractive index and the extinction coefficient, as a function of the wavelength, is very similar to the spectrum of transmittance and reflection. Indeed, one notices the presence of interference fringes. This behavior has not been reported elsewhere. The values and the behavior of the refractive index and the extinction coefficient ( $\mathrm{n}$ and $\mathrm{k}$ ) for the iron oxide thin films in the literature show a significant variation according to the elaboration techniques as well as the analytical methods used to extrapolate these parameters $[5,15,18]$.

To corroborate the ellipsometric results, regarding the energy band gap, with which deduced from spectrophotometry measurements, using the value of SE k data the absorption coefficient $\alpha$ was calculated from the equation [27]:

$$
\alpha=\frac{4 \pi k}{\lambda}
$$

The optical band gap $\left(E_{\mathrm{g}}\right)$ value is calculated according to a direct allowed transition from the general relation:

$$
(\alpha h v)^{2}=A\left(h v-E_{g}\right)
$$

The same method as that used for spectrophotometric measurements allows us to find a value of 2.04 $\mathrm{eV}$ for $E_{\mathrm{g}}$ (Fig. 7), this value is determined, that is nearly $5 \%$ of the calculated value using transmittance and reflectance measurements. The obtained optical parameters are summarized in Table 1 . These values agree with previously reported one, which varies between 1.9 and $2.2 \mathrm{eV}$, depends on the preparation techniques and crystalline structure and grain size of the $\alpha-\mathrm{Fe} 2 \mathrm{O} 3$ films [5, 15-22, 34].

\section{Summary And Conclusions}

In summary, a study of structural and optical properties of sprayed iron oxide $\mathrm{Fe}_{2} \mathrm{O}_{3}$ thin films has been presented. XRD analysis shows that the films crystallize in rhombohedral crystal system with space group R-3c and space group number 167 according to JCPDS card 33-0664. The SEM micrographs show a smooth and homogeneous surface of the thin films. Optical transmittance and reflectance measured with a spectrophotometer show an appearance of interferential fringes testifying the homogeneities of the obtained sprayed iron oxide thin films. According to the Tauc plot, the optical band gap has been found to be $2.17 \mathrm{eV}$, which is a typical value found in the literature. From ellipsometric measurements, refractive index and extinction coefficient have been deduced according to Cauchy model with an excellent MSE value (1.3) and the assumed thickness of the film close to $710 \mathrm{~nm}$ with no more than $2 \mathrm{~nm}$ roughness layer; this confirms the observation made by electron microscopy and the optical measurements. The optical band gap deduced from the value of absorption coefficient, via the extinction coefficient, has been found to be $2.04 \mathrm{eV}$.

\section{Acknowledgements}

The author would like to thank Pr. Dr. Tarek Ben Nasrallah for his technical support and fruitful discussions.

\section{References}

[1]. M. Mohapatra and S. Anand, International Journal of Engineering, Science and Technology, Vol. 2, No. 8, 2010 , p. 127.

[2]. Y. Huang, Z. Lin, M. Zheng, T. Wang, J. Yang, F. Yuan, X. Lu, L. Liu, D. Sun, Journal of Power Sources, Vol. 307, 2016 , p. 649.

[3]. M. M. Rahman, S. B. Khan, A. Jamal, M. Faisal, A.M. Aisiri (2011). Iron Oxide Nanoparticles, Nanomaterials, Prof. Mohammed Rahman (Ed.), ISBN: 978-953-307-913-4, InTech. www.intechopen.com/books/nanomaterials/iron-oxide-nanoparticles.

[4]. S. Boumaza, A. Boudjema, S. Omeiri, R. Bouarab, A. Bouguelia, M. Trari, Solar Energy, Vol. 84, 2010 , p.715.

[5]. F. Meydaneri Tezel, O. Özdemir, İ. Afsin Kariper, Surface Review and Letters, Vol. 24, No. 4, (2017) p. 1750051-1.

[6]. M. N. Batin, V. Popescu, Powder Metallurgy Progress, Vol. 11, 2011, No 3-4, p. 201.

[7]. J. H. Bang, K. S. Suslick, Journal of American Chemical Society, Vol. 129, 2007, p. 2242.

[8]. P. Tartaj, M. P. Morales, S. Veintemillas-Verdaguer, T. Gonzalez-Carreno, C. J. Serna, Synthesis, Handbook of Magnetic Materials, Elsevier: Amsterdam, the Netherlands, 2006, p. 403.

[9]. K. Tharani, L.C. Nehru, International Journal of Advanced Research in Physical Science, Vol. 2, Issue 8, 2015 , p. 47.

[10]. D. Penga, S. Beysena, Q. Li, Y. Suna, L. Yanga, Particuology, Vol. 8,2010, p.386.

[11]. A. S. Teja, P.Y. Koh, Progress in Crystal Growth and Characterization of Materials, Vol. 55, 2009 , p. 22.

[12]. M. A. Aegerter, C. O. Avellaneda, A. Pawlika, M. Atik, Journal of Sol-Gel Science and Technology, Vol. 8, 1997 , p. 689.

[13]. M.N. Batin, V. Popescu, Optoelectronics and Advanced Materials, Rap. Comm., Vol. 6, No. 7-8, 2012 , p. 727.

[14]. M. Saleem, M.F. Al-Kuhaili, S. M. A. Durrani, I. A. Bakhtiari, Physica Scripta, Vol. 85, 2012, 055802, p.1.

[15]. M.F. Al-Kuhaili, M. Saleem, S. M. A. Durrani, Journal of Alloys and Compounds, Vol. 521, 2012, p. 178.

[16]. M. Bender, E. Gagaoudakis, E. Douloufakis, E. Natsakou, N. Katsarakis, V. Cimalla, G. Kiriakidis, E. Fortunato, P. Nunes, A. 
Marques, R. Martins, Thin Solid Films, Vol. 418, 2002, p. 45.

[17]. P. Nunes, E. Fortunato, R. Martins, Thin Solid Films Vol. 383, 2001, p. 277.

[18]. A.A. Akl, Applied Surface Science, Vol. 233, 2004, p.307.

[19]. W.B. Ingler Jr., S.U.M. Khan, International Journal Hydrogen Energy, Vol. 30, 2005, p. 821.

[20]. R.V. Todorovska, St. Groudeva-Zotova, D.S. Todorovsky, Materials Letters, Vol. 56, 2002, p. 770.

[21]. L. Dghoughi, B. Elidrissi, C. Bernède, M. Addou, M. Alaoui Lamrani, M. Regragui, H. Erguig, Applied Surface Science, Vol. 253, 2006, p. 1823.

[22]. B. Ouertani, J. Ouerfelli, M. Saadoun, H. Ezzaouia, B. Bessaïs, Thin Solid Films, Vol. 516, 2008, p. 8584.

[23]. A. Altomare, N. Corriero, C. Cuocci, A. Falcicchio, A. Moliterni, R. Rizzi, "QUALX2.0: A qualitative phase analysis software using the freely available database POW_COD", Journal of Applied Crystallography, Vol. 46, 2015, p. 598.

[24]. S. Belgacem, R. Bennaceur, Revue de Physique Appliquée, Vol. 25, 1990, p. 1245.

[25]. D. Bhattacharyya, S. Chaudhuri, A. K. Pal, Vacuum, Vol. 43, No. 4, 1992, p. 313.

[26]. A. Amlouk, K. Boubaker, M. Bouhafs, M. Amlouk, Journal of Alloys and Compounds, Vol. 509, 2011, p. 3661.

[27]. Mark Fox, Optical properties of solids, Oxford University Press, 2001.

[28]. J. A. Woollam, B. Johs, C. M. Herzinger, J. Hilfiker, R. Synowicki, C. L Bungay, Critical Reviews CR 72, 3 (1999).

[29]. J.A. Woollam, P.G. Snyder, "Variable Angle Spectroscopic Ellipsometry", book chapter for Encyclopedia of Materials Characterization, Butterworth Publishers, Greenwich, 1992.

[30]. W. A. McGahan, B. Johs, J. A. Woollam, Thin Solid Films, Vol. 234, 1993, p. 443.

[31]. B. Johs, R. H. French, F. D. Kalk, W. A. McGahan, J. A. Woollam, Optical Interference Coatings, SPIE Vol. 2253, 1994, Edited by F. Abeles, p. 1098

[32]. M. Gartner, M. Crisan, A. Jitianu, R. Scurtu, R. Gavrila, I. Opera, M. Zaharescu, Journal of Sol-Gel Science and Technology, Vol. 26, 2003, p. 745

[33]. S. Riaz, H. Yousaf, S. Islam, Z. N. Kayani, S. Naseem, The 2016 World Congress on Advanced in Civil, Environmental, and Materials Research (ACEM16) Jeju Island, Korea, August 28-September 1, 2016.

[34]. I. Jõgi, T. Jesper Jacobsson, M. Fondell, T. Wätjen, Jan-Otto Carlsson, M. Boman, T. Edvinsson, Langmuir, Vol. 31, 2015, p.12372.

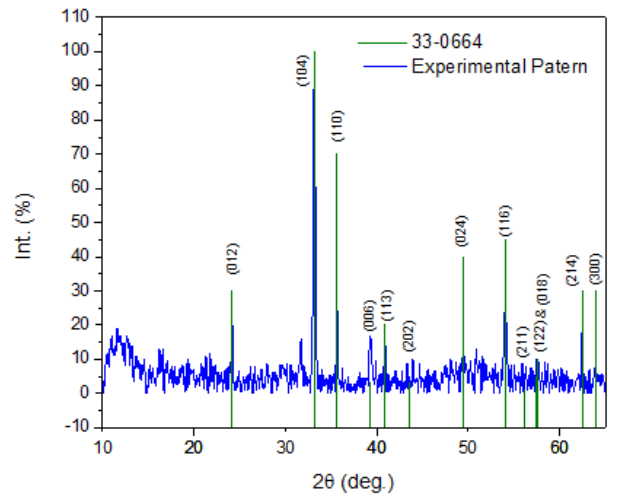

Fig. 1 XRD patterns of sprayed and annealed $\square-\mathrm{Fe}_{2} \mathrm{O}_{3}$ thin films
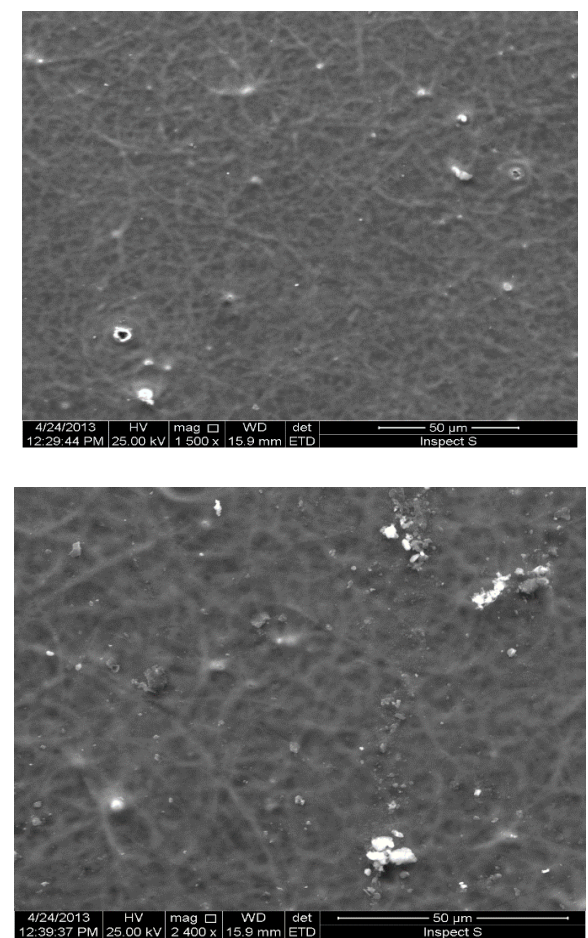


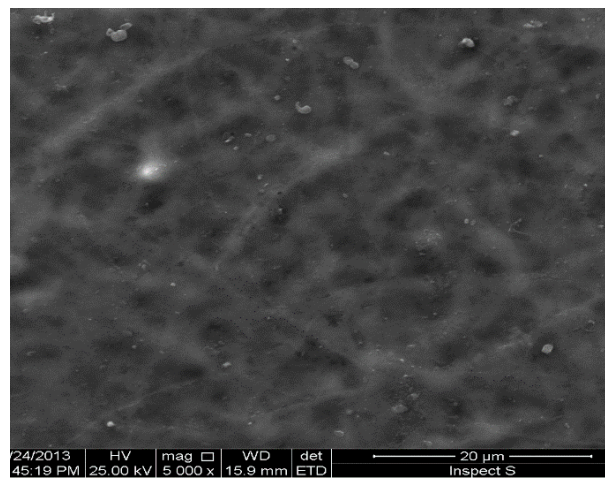

Fig. 2 SEM images of sprayed and annealed iron oxide thin films.

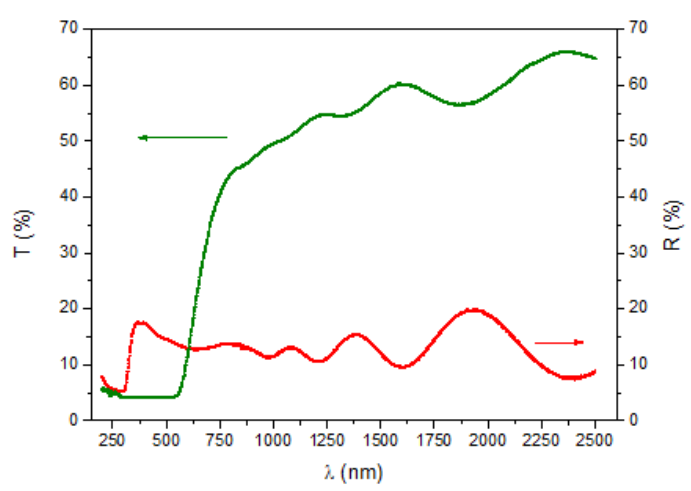

Fig. 3 Optical transmittance $T$ and reflectance R spectra as a function of the wavelength $\square$ of sprayed $\square-\mathrm{Fe}_{2} \mathrm{O}_{3}$ thin film deposited on glass $\left(\mathrm{Ts}=400{ }^{\circ} \mathrm{C}, \mathrm{d} \approx 1 \square \mathrm{m}\right)$.

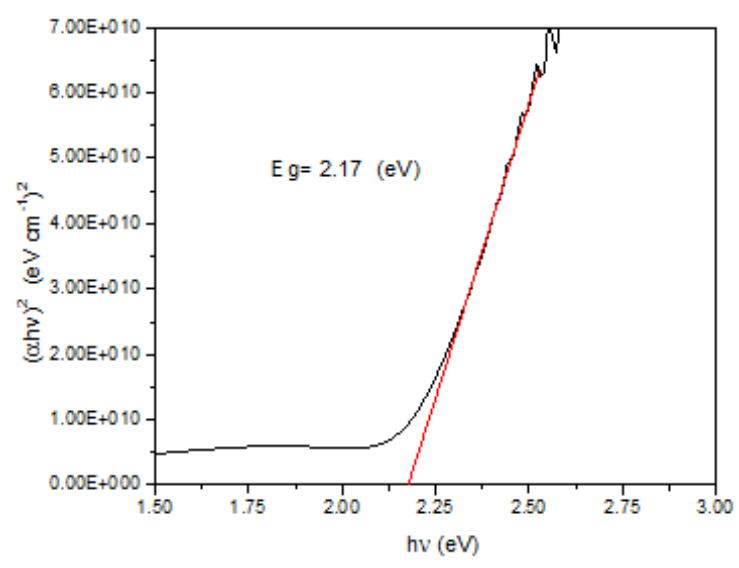

Fig 4. ( $\square \mathrm{h} \square \mathcal{3}$ versus $\mathrm{h} \square \square$ plot of sprayed $\square-\mathrm{Fe}_{2} \mathrm{O}_{3}$ thin film (Ts $=400^{\circ} \mathrm{C}, \mathrm{d} \approx 1 \square \mathrm{m}$ ).

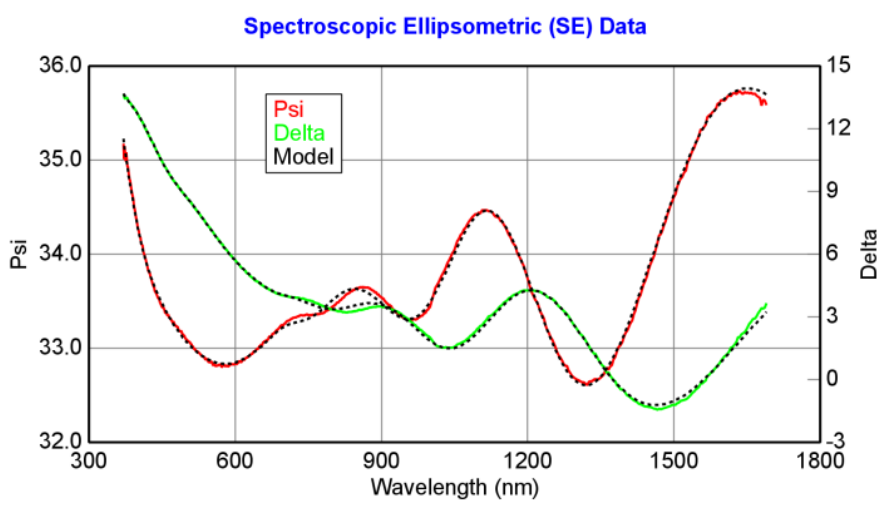

Fig. 5 Typical Experimental and fitted ellipsometric $\Psi$ and $\Delta$ spectra. 


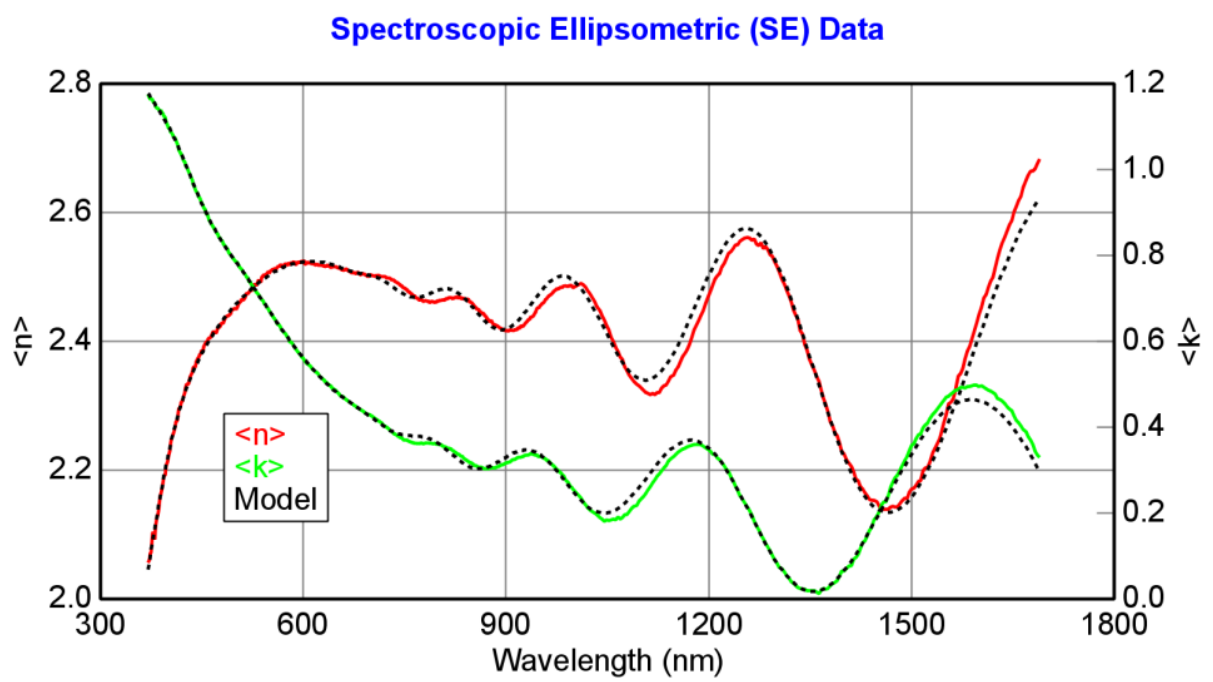

Fig. 6 Refractive index $\mathrm{n}$ and extinction coefficient $\mathrm{k}$ as a function of the wavelength of sprayed and annealed $\square-\mathrm{Fe}_{2} \mathrm{O}_{3}$ films.

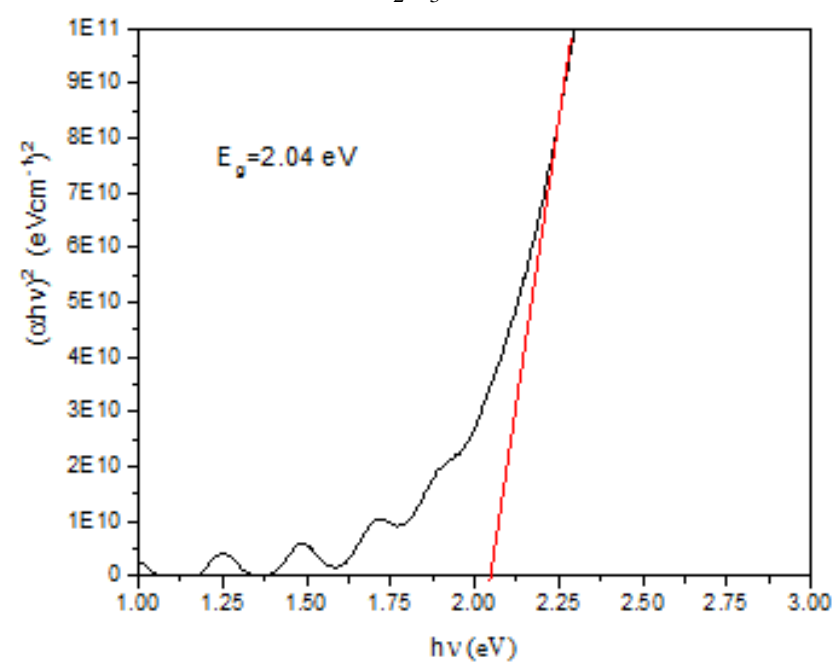

Fig. 7 ( $\square \mathrm{h} \square \mathcal{\jmath}$ versus $\mathrm{h} \square \square$ plot osprayed and annealed $\square-\mathrm{Fe}_{2} \mathrm{O}_{3}$ thin films from ellipsometric data.

Table 1. Optical constants of $\square-\mathrm{Fe} 2 \mathrm{O} 3$ sprayed and annealed thin films.

\begin{tabular}{|c|c|c|}
\hline & $\mathrm{T}$ and $\mathrm{R}$ measurements & Ellipsometric measurements \\
\hline Thickness & $900 \pm 10 \mathrm{~nm}$ & $710.35 \pm 0.35 \mathrm{~nm}$ \\
\hline $\mathrm{E}_{\mathrm{g}}$ & $2.17 \pm 0.1 \mathrm{eV}$ & $2.04 \pm 0.05 \mathrm{eV}$ \\
\hline MSE & --- & 1.308 \\
\hline Roughness & --- & $1.65 \pm 0.08 \mathrm{~nm}$ \\
\hline n @ 632.8nm & 2.8 & 2.604 \\
\hline k@ @ $632.8 \mathrm{~nm}$ & 0.55 & 0.478 \\
\hline
\end{tabular}

